\title{
Prognostic value of myocardial perfusion scintigraphy in type 2 diabetic patients with mild, stable angina pectoris
}

\author{
Jacobijne J. Wiersma, MD, PhD, ${ }^{\text {a }}$ Hein J. Verberne, MD, PhD, ${ }^{\mathrm{b}}$ Wik L. ten Holt, \\ $M D,{ }^{c}$ Ineke M. Radder, ${ }^{a}$ Lea M. Dijksman, MSc, ${ }^{a}$ Berthe L. F. van Eck-Smit, MD, \\ PhD, ${ }^{\mathrm{b}}$ Mieke D. Trip, MD, PhD, ${ }^{\mathrm{a}}$ Jan G. P. Tijssen, PhD, ${ }^{\mathrm{a}}$ and Jan J. Piek, MD, PhD ${ }^{\mathrm{a}}$
}

Aim. To determine the prognostic value of reversible myocardial perfusion defects on myocardial perfusion scintigraphy (MPS) in patients with type 2 diabetes mellitus and mild anginal complaints.

Methods and results. In the MERIDIAN trial, patients with diabetes mellitus type 2, stable, mild anginal symptoms (Canadian Cardiovascular Society classification (CCS) I-II/IV) and reversible perfusion defects were randomized to either continued pharmacological treatment or early invasive treatment. In this sub analysis, the severity of the myocardial perfusion defect was related to the occurrence of cardiac death and non-fatal myocardial infarction, in 319 patients (63\% male, $65 \pm 9$ years). During follow-up ( $2.2 \pm 0.6$ years $), 14$ patients had a cardiac event: 3 in 171 patients without myocardial ischemia and 11 in 148 patients with myocardial ischemia. Annual event rates rose from $0.8 \%$ to $5.8 \%$ with increasing severity of myocardial ischemia. Multivariable analysis identified the presence of severe myocardial ischemia (hazard ratio (HR) 5.45, 95\% CI 1.89-15.71) and insulin use (HR 4.00, 95\% CI 1.25-12.75) as independent predictors of cardiac events.

Conclusions. Type 2 diabetics with mild anginal symptoms with no or moderate myocardial ischemia have a low annual cardiac event rate. In patients with severe myocardial ischemia event rate increased 3-6 fold. (J Nucl Cardiol 2009;16:524-32.)

Key Words: Diabetes mellitus, type $2 \cdot$ angina pectoris $\cdot$ myocardial ischemia $\bullet$ SPECT $•$ prognosis

See related editorial, pp. 486-489

\section{INTRODUCTION}

To date, approximately 150 million people worldwide are diagnosed with type 2 diabetes mellitus and

From the Department of Cardiology, ${ }^{\mathrm{a}}$ and Nuclear Medicine, ${ }^{\mathrm{b}}$ Academic Medical Center, Amsterdam; Department of Cardiology, Amstelland Hospital, Amstelveen, The Netherlands.

Received for publication Jun 25, 2008; final revision accepted Jun 5, 2009.

Reprint requests: Jacobijne J. Wiersma, MD, PhD, Department of Cardiology, Academic Medical Center, Meibergdreef 9, 1105AZ Amsterdam, The Netherlands; j.j.wiersma@amc.uva.nl.

$1071-3581 / \$ 34.00$

Copyright (C) 2009 by the The Author(s). This article is published with open access at Springerlink.com

doi:10.1007/s12350-009-9111-z this number is expected to double before $2025 .{ }^{1}$ Diabetic patients are at a 2-4 fold higher risk of coronary artery disease (CAD). ${ }^{2}$ Furthermore, in diabetics CAD develops at a younger age and, when $\mathrm{CAD}$ becomes overt, these patients have a poor cardiovascular prognosis. ${ }^{2-4}$ Finally, approximately $75 \%$ of patients with diabetes mellitus type 2 will die from a cardiac cause. ${ }^{4}$

Patients with diabetes mellitus are more likely to have an atypical or less distinct expression of their anginal symptoms. Myocardial ischemia is already present in $\pm 20 \%$ of asymptomatic patients with type 2 diabetes mellitus. ${ }^{5}$ Early recognition of CAD is warranted to install dietary and lifestyle adaptation, pharmacological risk factor modification and optimization of anti-anginal treatment.

Several (sub)-studies have reported on the prognostic value of myocardial perfusion defects on MPS in a variety of diabetic patients. However, limited information is available on the significance of myocardial ischemia as assessed with MPS in type 2 diabetic patients 
with mild anginal complaints (Canadian Cardiovascular Society classification (CCS) I-II/IV). ${ }^{6-8}$ Therefore, the purpose of this study was to determine the prognostic value of myocardial ischemia, as assessed with myocardial perfusion scintigraphy (MPS), in a well-defined patient population with type 2 diabetes mellitus and mild, stable anginal complaints (CCS I-II/IV).

\section{METHODS}

\section{Setting}

This study consisted of 319 patients who underwent a MPS to establish eligibility for the randomized multicenter MERIDIAN trial (Multicenter trial of Early Revascularization In patients with DIabetes mellitus and mild ANginal symptoms) at the Cardiology and Internal Medicine out-patient clinics of 26 Dutch hospitals (see Appendix for participating centers). Detailed descriptions of the study design and of the principal results have been published previously. ${ }^{9}$ The aim of the MERIDIAN trial was to investigate if an early coronary revascularization strategy would reduce cardiovascular complications in patients with type 2 diabetes mellitus and mild, stable anginal symptoms (CCS I-II/IV). Only patients with myocardial ischemia as assessed with MPS were eligible for randomization to an early invasive approach including coronary angiography and revascularization if feasible or a continued pharmacological treatment. Patients without myocardial ischemia on MPS were treated according to local routine.

The trial was based on an intention to treat principle and was complied with the Declaration of Helsinki. The medical ethical committees of the participating centers approved the protocol. All patients gave written informed consent before MPS.

The MERIDIAN trial was prematurely terminated because of a too slow recruitment rate. Although the study was now underpowered to test the hypothesis, no differences between the treatment strategies were observed. ${ }^{9}$ In view of the lack of difference between the two treatment strategies, the current analysis on the prognostic value of myocardial perfusion defects ignores the differences in (randomized) treatment, therefore all patients with reversible defects, including patients who underwent revascularization and patients who were treated medically, were included in the analysis.

\section{Study Population}

Inclusion and exclusion criteria have previously been described. In short patients $\geq 30$ years with mild, stable ( $\geq 2$ months) complaints of angina pectoris (CCS class I-II/IV) and type 2 diabetes mellitus were eligible for screening. Medical treatment was considered mandatory based upon the symptomatic status of the patients. Type 2 diabetes mellitus was defined as having either one of the following: fasting glucose of $>7.0 \mathrm{mmol} / \mathrm{L}$ or non-fasting glucose $>11.0 \mathrm{mmol} / \mathrm{L}$ in 2 samples on 2 separate days; treatment with oral antidiabetic medication; treatment with insulin following initial treatment with oral anti-diabetic medication; or onset of insulin treatment at age $\geq 50$ years.

All patients underwent initial clinical evaluation prior to MPS. ECG-abnormalities were defined as the presence of ST-T abnormalities, Q-waves, T-wave inversion or left bundle branch block. All patients were followed at the out-patient clinic until January 1st, 2006, for the occurrence of cardiac death and spontaneous, non-procedural related, non-fatal MI. All deaths were considered cardiac unless an unequivocal noncardiac cause can be established. The events were independently reviewed by the senior author (JP), who was not aware of the patients treatment allocation and the MPS data. Myocardial infarctions were defined as CK MB levels greater than or equal to twice the upper limit of normal. Procedural-related infarctions were excluded from the analyses.

\section{Myocardial Perfusion Scintigraphy}

Stress and rest myocardial perfusion scintigraphy (with single-photon emission computed tomography (SPECT)) was performed with ${ }^{99 \mathrm{~m}} \mathrm{Tc}$ labeled perfusion tracers (Tetrofosmin or sesta-MIBI) or Thallium-201, according to the guidelines of the American Society of Nuclear Cardiology. ${ }^{10,11}$ The use of ECGgated SPECT was at the discretion of the nuclear physician.

Symptom limited exercise (bicycle or treadmill ergometry) was the preferred stress modality. Pharmacological vasodilatory stress with adenosine or dipyridamole was applied if there was insufficient increase of heart rate $(<85 \%$ age predicted maximal heart-rate) during physical exercise, in the presence of a left bundle branch block, or if the anti-anginal medication had not been adequately discontinued beforehand. $^{11}$

Dobutamine stress testing was performed in patients with a contra-indication for adenosine or dipyridamole.

\section{Image Analysis}

A local panel of 2-3 nuclear physicians analyzed the images using a 17 myocardial segment model. Segments were scored with a 5 -point scoring system $(0=$ normal; $1=$ equivocal; $2=$ moderate reduction; $3=$ severe reduction; $4=$ absent activity). Summed stress score (SSS) and summed rest score (SRS) were obtained by adding the scores of all segments of stress and rest images, respectively. The summed difference score (SDS) was calculated by subtracting the SRS from the SSS. Reversible myocardial perfusion defects, indicative for myocardial ischemia, were defined as SDS $\geq 3$. The MPS outcome for reversible defects was further categorized into: no ischemia (SDS < 3); moderate ischemia (SDS 3-7) and severe ischemia (SDS of 8 or higher (SDS $\geq 8$ )). Fixed defects (defects also present at rest) were defined as $\mathrm{SRS} \geq 3$. Any perfusion abnormality was defined as SDS $\geq 3$ and/or SRS $\geq 3$. $^{12}$

\section{Statistical Analysis}

Data are presented as number of patients and proportion or as mean \pm standard deviation (SD). Continuous variables 
with Gaussian distributions were compared by Student's unpaired $t$ test or Mann-Whitney test; categorical variables were compared by $\chi^{2}$ or Fisher's exact test where appropriate.

The annual event rates were calculated by dividing the actual number of events by the total exposure years. KaplanMeier cumulative survival rates were compared using the logrank test. Cox proportional hazards regression was used to determine independent predictors of cardiac death or non-fatal MI. Criterion for entry of variables into the multivariable analysis was set on $P \leq .2$. The predictive value was expressed as the hazard ratio (HR) with corresponding $95 \%$ confidence intervals (CI). The discriminating value of this model was calculated by $\mathrm{C}$-index. The SPSS package for windows version 12.0 (SPSS Inc, Chicago, IL, USA) was used for these purposes. Values of $P<.05$ were considered statistically significant.

\section{RESULTS}

\section{Baseline Characteristics}

Between October 2002 and July 2004, 329 patients were referred for MPS as part of the screening phase of the MERIDIAN trial. Ten patients were excluded from the present analysis because of crescendo angina pectoris during MPS (2), inconclusive MPS (2), or withdrawal of consent (6). The remaining 319 patients were eligible for the current analysis (Figure 1). One patient, however, withdrew his consent after the first follow-up visit.

The baseline characteristics are described in Table 1. The distribution of classical cardiac risk factors was typical for a diabetic population. The mean duration of diabetes was 8 years, and $38 \%$ of the patients were insulin dependent. Almost half of patients (47\%) had documented coronary artery disease (PCI, MI or CABG). Of all patients, $84 \%$ were on aspirin, $73 \%$ on lipid-lowering therapy and $73 \%$ on beta-blockade.

\section{MPS Results}

Of 319 patients, $200(63 \%)$ adequately performed an exercise test, in 113 patients $(36 \%)$ vasodilatory stress was applied, and in $6(2 \%)$ dobutamine stress test was performed. In $290(91 \%)$ patients ${ }^{99 \mathrm{~m}} \mathrm{Tc}$-labeled perfusion tracers were used. Semi-quantitative scores are described in Table 1. Perfusion abnormalities (fixed or reversible) were found in $208(65 \%)$ patients; 60 (19\%) had only fixed defects, 78 (24\%) mixed defects and $70(22 \%)$ patients had only reversible defects. Thus, 148 (46\%) patients showed reversible perfusion defects; $85(26 \%)$ patients had moderate and $63(20 \%)$ severe ischemia. These 148 patients were eligible for randomization into the MERIDIAN trial, 76 patients were

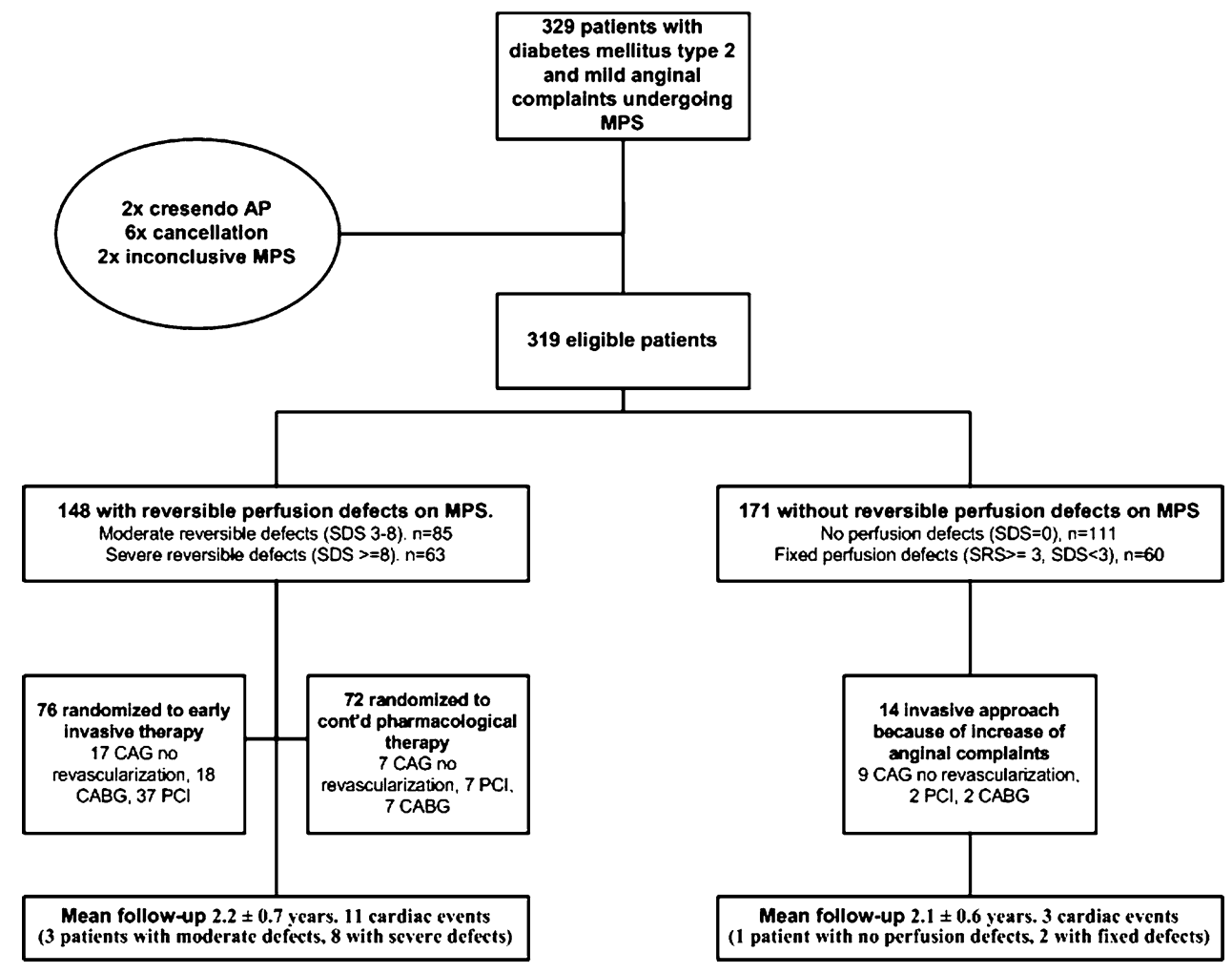

Figure 1. Study design. 
Table 1. Clinical characteristics and myocardial perfusion scintigraphic parameters

\begin{tabular}{|c|c|c|c|c|}
\hline & $\begin{array}{c}\text { All } \\
\text { patients } \\
\mathrm{n}=\mathbf{3 1 9}\end{array}$ & $\begin{array}{c}\text { No } \\
\text { myocardial } \\
\text { ischemia } \\
n=171\end{array}$ & $\begin{array}{c}\text { Myocardial } \\
\text { ischemia } \\
n=148\end{array}$ & P-value \\
\hline \multicolumn{5}{|l|}{ Clinical characteristics } \\
\hline Male & $201(63)$ & $93(54)$ & $108(73)$ & .001 \\
\hline Age (years) & $65(9)$ & $64(9)$ & $66(9)$ & .04 \\
\hline CCS II/IV & $130(41)$ & $61(36)$ & $69(47)$ & .05 \\
\hline \multicolumn{5}{|l|}{ Medical history (\%) } \\
\hline Previous MI & $92(29)$ & $43(25)$ & $49(33)$ & \\
\hline Previous PCI & $87(27)$ & $55(32)$ & $32(22)$ & .04 \\
\hline Previous CABG & $56(18)$ & $30(18)$ & $26(18)$ & \\
\hline Duration diabetes (years) & $8(7)$ & $8(7)$ & $8(7)$ & \\
\hline$<5$ years & $119(38)$ & $62(38)$ & $57(39)$ & \\
\hline$>10$ years & $92(30)$ & $46(28)$ & $46(31)$ & \\
\hline Insulin & $122(38)$ & $67(39)$ & $55(37)$ & \\
\hline \multicolumn{5}{|l|}{ Risk factors (\%) } \\
\hline Hypertension & $176(55)$ & $98(57)$ & $78(53)$ & \\
\hline Smoking & $56(18)$ & $26(15)$ & $30(20)$ & \\
\hline Previous smoker & $162(51)$ & $84(49)$ & $78(53)$ & \\
\hline Family history & $116(36)$ & $71(42)$ & $45(30)$ & .04 \\
\hline Hypercholesterolemia & $201(63)$ & $108(63)$ & $93(63)$ & \\
\hline $\begin{array}{l}\text { Body mass index } \mathrm{kg} / \mathrm{m}^{2} \\
\text { (BMI) }\end{array}$ & $29.4(4)$ & $30(4)$ & $29(4)$ & \\
\hline Normal, $<24.9$ & $36(11)$ & $17(10)$ & $19(13)$ & \\
\hline Obesitas, I > 29.9 & $128(40)$ & $69(41)$ & $59(40)$ & \\
\hline \multicolumn{5}{|l|}{ Drug therapy (\%) } \\
\hline Aspirin & $268(84)$ & $140(82)$ & $128(87)$ & \\
\hline Statin & $233(73)$ & $130(76)$ & $103(70)$ & \\
\hline ACE-inhibition & $130(41)$ & $74(43)$ & $56(38)$ & \\
\hline Beta blockade & $233(73)$ & $128(75)$ & $105(71)$ & \\
\hline Long-acting nitrate & $122(38)$ & $52(30)$ & $70(47)$ & .002 \\
\hline Calcium-antagonist & $139(44)$ & $64(37)$ & $75(51)$ & .02 \\
\hline Insulin & $122(38)$ & $67(39)$ & $55(37)$ & \\
\hline ECG-abnormalities & $158(50)$ & $72(42)$ & $86(58)$ & .004 \\
\hline \multicolumn{5}{|l|}{ MPS results } \\
\hline SSS & $8(8)$ & $4.4(6.8)$ & $12.3(6.8)$ & $<.001$ \\
\hline SRS & $4.3(6)$ & $3.9(6.7)$ & $4.8(6.1)$ & \\
\hline SDS & $3.7(4.5)$ & $0.4(0.7)$ & $7.5(4.0)$ & $<.001$ \\
\hline Any perfusion abnormality & $208(65)$ & $60(35)$ & $148(100)$ & \\
\hline At least one fixed defect* & $138(43)$ & $60(35)$ & $78(53)$ & \\
\hline
\end{tabular}

Values are presented as $\mathrm{n}(\%)$ or as mean (SD) unless otherwise indicated.

$C C S$, Canadian Cardiovascular Society; $M I$, myocardial infarction; $P C I$, percutaneous coronary intervention; $C A B G$, coronary artery bypass grafting; $A C E$, angiotensin-converting enzyme; SSS, summed stress score; SRS, summed rest score; SDS, summed difference score.

*Also included patients with mixed defects: fixed and reversible.

randomized to early invasive treatment and 72 patients to continued pharmacological treatment.

Patients with reversible defects were older, predominantly male, had a higher prevalence of CCS II/IV, and were less likely to have undergone PCI procedures. Furthermore, these patients received more intensive anti-anginal therapy and had more ECG-abnormalities (Table 1). 


\section{Symptom-Driven Interventions}

A description of the coronary interventions performed during follow-up, not including randomization driven procedures, is presented here. Of the 148 patients with reversible defects, the interventions are presented in relation to the treatment strategies. During follow-up, $13(8 \%)$ of the 171 patients without reversible defects had an increase of their anginal complaints and underwent elective, coronary angiography. Subsequent revascularization was performed in $3(2 \%)$ of these patients. Furthermore, one patient underwent a rescueCABG after MI.

Of 72 patients with reversible myocardial perfusion defects, randomized to continued pharmacological treatment, $18(25 \%)$ underwent elective coronary angiography and 11 (15\%) underwent subsequent revascularization. In 3 patients (4\%) with an acute MI a primary PCI (2) or rescue-CABG (1) was performed. One patient underwent a repeat PCI after 10 months for in-stent restenosis.

All 76 patients assigned to early invasive treatment underwent CAG. No or only non-significant coronary abnormalities were detected in $17(23 \%)$ patients. In 3 patients (2 patients with single-vessel disease and 1 patient with multi-vessel disease) no intervention was possible and 1 patient refused further treatment. Of the remaining patients, 37 were referred for PCI and 18 for CABG. One patient underwent repeat CABG 2 years after the randomization-driven CABG. Furthermore, 1 patient underwent primary PCI for an acute MI, 9 months after the randomization-driven PCI.

\section{Cardiac Events}

A description of events per MPS category is presented in Table 2. The mean follow-up period of 148 patients with and 171 patients without reversible defects was $2.2 \pm 0.7$ and $2.1 \pm 0.6$ years, respectively (minmax: 2.3-38.5 months). During follow-up 3 of 171 $(1.8 \%)$ patients without reversible defects, 3 of 83 patients with moderate ischemia and 8 of 65 patients with severe ischemia on MPS had a non-fatal myocardial infarction or died from a cardiac cause. The differences in event rate between patients without and patients with moderate or severe ischemia were statistically significant $(P=.004)$.

Calculated annual event rates were 0.8 for patients without defects, and 1.5 and 5.8 for patients with respectively moderate and severe ischemia. KaplanMeier curves for the occurrence of cardiac death or nonfatal MI are shown in Figure 2. The pattern of the three survival curves was preserved when the data were analyzed by randomized treatments (data not shown).

\section{Variables Associated with the Occurrence of the Combined Endpoint}

The frequencies and hazard ratios of the different clinical and diagnostic variables are shown in Table 3.

Table 2. The occurrence of events described per MPS category

\begin{tabular}{|c|c|c|c|c|c|c|c|c|c|}
\hline \multirow[b]{2}{*}{$\begin{array}{l}\text { Clinical } \\
\text { events }\end{array}$} & \multicolumn{3}{|c|}{$\begin{array}{c}\text { No myocardial ischemia } \\
\text { (SDS < 3) }\end{array}$} & \multicolumn{3}{|c|}{$\begin{array}{c}\text { Myocardial ischemia } \\
\text { (SDS } \geq 3)\end{array}$} & \multicolumn{3}{|c|}{ P-value* } \\
\hline & $\begin{array}{c}\text { No } \\
\text { defects } \\
(n=111)\end{array}$ & $\begin{array}{c}\text { Only } \\
\text { fixed } \\
(n=60)\end{array}$ & $\begin{array}{c}\text { Total } \\
(\mathbf{n}=171)\end{array}$ & $\begin{array}{c}\text { Total } \\
(\mathrm{n}=148)\end{array}$ & $\begin{array}{l}\text { SDS 3-7 } \\
(\mathrm{n}=\mathbf{8 5})\end{array}$ & $\begin{array}{l}\text { SDS } \geq 8 \\
(n=63)\end{array}$ & $\begin{array}{c}\text { SDS } \\
<3 \\
\text { VS } \\
\text { SDS } \\
3-7\end{array}$ & $\begin{array}{c}\text { SDS } \\
<3 \\
\text { vs } \\
\text { SDS } \\
\geq 8\end{array}$ & $\begin{array}{c}\text { SDS } \\
3-7 \\
\text { vs } \\
\text { SDS } \\
\geq 8\end{array}$ \\
\hline $\begin{array}{l}\text { Composite } \\
\text { events }\end{array}$ & $1(0.4)$ & $2(1.6)$ & $3(0.8)$ & $11(3.3)$ & $3(1.5)$ & $8(5.8)$ & - & $<.001$ & .01 \\
\hline Cardiac death & $0(0)$ & $1(0.8)$ & $1(0.3)$ & $7(2.1)$ & $2(1.0)$ & $5(3.6)$ & - & .02 & $<.04$ \\
\hline Non-fatal MI & $1(0.4)$ & $1(0.8)$ & $2(0.5)$ & $7(2.1)$ & $2(1.0)$ & $5^{\#}(3.6)$ & - & .01 & - \\
\hline $\begin{array}{l}\text { Hospitalization } \\
\text { UAP }\end{array}$ & $4(1.6)$ & $2(1.6)$ & $6(1.6)$ & $4(1.2)$ & $4(2.0)$ & $0(0)$ & - & - & - \\
\hline $\begin{array}{l}\text { All-cause } \\
\text { mortality }\end{array}$ & $1(0.4)$ & $4(3.1)$ & $5(1.4)$ & $11(3.2)$ & $4(2.0)$ & $7(4.9)$ & - & - & - \\
\hline
\end{tabular}

All clinical events are described as $\mathrm{n}$ (annual event rate). Composite events taking account of the first occurrence of cardiac death or non-fatal MI.

$M I$, Myocardial infarction; UAP, unstable angina pectoris.

\# One myocardial infarction was procedure related this MI was not considered as a cardiac event for the current analyses. 


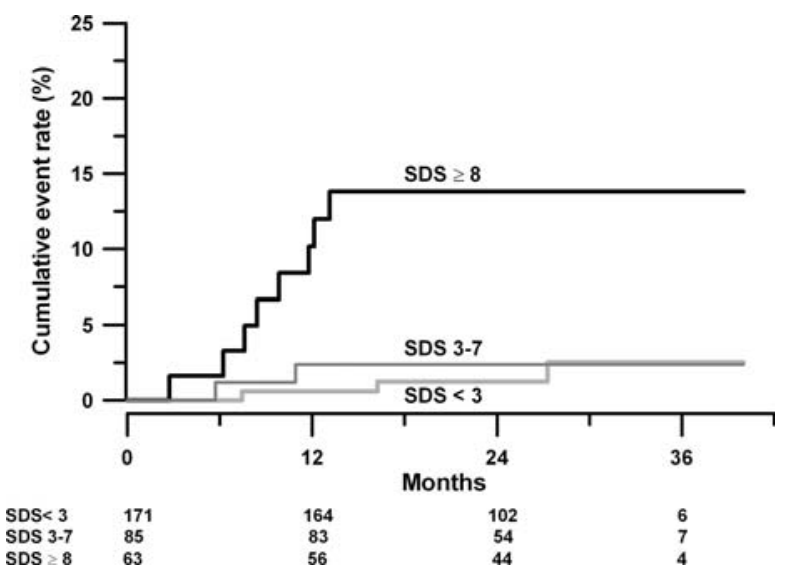

Figure 2. Kaplan-Meier estimates of the cumulative rate of cardiac death or non-fatal MI, related to the MPS outcome. Kaplan-Meier cumulative event rates estimates for the occurrence of the cardiac death or non-fatal MI by the presence or absence of myocardial perfusion defects. Black line $=$ $\mathrm{SDS} \geq 8 ;$ dark grey $=\mathrm{SDS} 3-7 ;$ light grey $=\operatorname{SDS}<3$. Cumulative curves according to the severity of myocardial ischemia of all patients without myocardial ischemia compared to all patients with reversible myocardial ischemia.

In multivariable analysis, severe myocardial ischemia $(\mathrm{SDS} \geq 8)(\mathrm{HR} 5.45,95 \%$ CI $1.89-15.71, P \leq .001)$, and the use of insulin (HR 4.00, 95\%CI 1.25-12.75, $P \leq .02$ ) were independent predictors of cardiac death and nonfatal MI. Previous myocardial infarction did not reach statistical significance as an independent predictor of events (HR 2.93, 95\% CI 0.99-8.78, $P=.05$ ). The deviance $(-2 \mathrm{log}$ likelihood) of the model including previous MI and insulin is 128.215. The change from the previous (chi square) by adding MPS outcome is 11.363 , $P<.001$. The C-index of MPS outcome as a single variable is 0.726 , whereas the $\mathrm{C}$-index of previous $\mathrm{MI}$ and insulin use is 0.737 . The combination MPS outcome, previous $\mathrm{MI}$ and insulin use results in a $\mathrm{C}$-index of 0.838 . We can conclude that the variable MPS outcome therefore adds approximately $10 \%$ to the model.

\section{DISCUSSION}

In this study, we have shown that in almost $50 \%$ of patients with type 2 diabetes mellitus and mild angina pectoris myocardial ischemia is present. Secondly, we have shown that severe myocardial ischemia is an independent predictor for cardiac events. In addition to the severity of myocardial ischemia, the use of insulin is an independent predictor of cardiac death and non-fatal MI. Patients without myocardial ischemia are at a low annual risk, irrespective of the presence of fixed defects $(0.4-0.8 \%)$.

\section{Comparison with Previous Studies}

Several reports have been published on the use of MPS in diabetic patients. $5,6,8,13-15$ One of these studies

Table 3. Frequencies and hazard ratios of the occurrence of cardiac death or non-fatal MI according to the presence of a characteristic

\begin{tabular}{lccccc}
\hline \multicolumn{1}{c}{ Characteristic } & Present & Absent & $\begin{array}{c}\text { Univariable } \\
\text { HR (95\%) CI }\end{array}$ & $\begin{array}{c}\text { Multivariable } \\
\text { HR (95\%) CI }\end{array}$ & P-value \\
\hline Male gender & $9 / 201$ & $5 / 118$ & $1.09(0.36-3.25)$ & \\
CCS II/IV & $3 / 130$ & $11 / 189$ & $0.39(0.11-1.38)$ & \\
BMI $\geq 29.9 \mathrm{~kg} / \mathrm{m}^{2}(\mathrm{n}=315)$ & $8 / 128$ & $6 / 187$ & $1.71(0.57-5.08)$ & \\
Age 65 years or older & $10 / 168$ & $4 / 151$ & $2.08(0.64-6.74)$ & \\
Previous MI & $7 / 92$ & $7 / 227$ & $2.94(0.99-8.75)^{*}$ & \\
Previous revascularization & $7 / 121$ & $7 / 198$ & $1.63(0.57-4.67)$ & & \\
Aspirin & $14 / 268$ & $0 / 51$ & $26.53(0.06-11990)$ & & \\
Statin & $11 / 233$ & $3 / 86$ & $1.21(0.33-4.41)$ & & \\
Insulin & $10 / 122$ & $4 / 197$ & $4.25(1.33-13.57)^{*}$ & $4.00(1.25-12.75)$ & .02 \\
Abnormal rest ECG & $11 / 158$ & $3 / 161$ & $3.44(0.95-12.50)^{\ddagger}$ & & \\
MPS: Severe ischemia & $8 / 63$ & $6 / 256$ & $5.70(2.00-16.60)^{*}$ & $5.446(1.89-15.71)$ & $\leq .001$ \\
\hline
\end{tabular}

Variables are described as the number of patients with the event in relation to the total amount of patients with this characteristic. The variables: a history of MI, use of insulin and severe ischemia on MPS (SDS $\geq 8$ ) were entered in the Cox proportional hazards model.

$H R$, Hazard ratio; $C I$, confidence interval; $L B B B$, left bundle branch block; $E F$, ejection fraction; other abbreviations as described in Table 1.

${ }^{\star} P<.1 ;{ }^{*} P<.05$ in the univariable analysis. 
was performed in asymptomatic diabetic patients, and they stated that ischemia was already present in $20 \%$ of diabetics without any anginal complaint. However, both the abovementioned study as well as others concerned the value of MPS in asymptomatic diabetic patients, or in symptomatic patients in whom the classification of anginal complaints was not provided. To our knowledge, our study is the first to assess the prognostic value of MPS in patients with type 2 diabetes mellitus and welldefined, mild angina pectoris, CCS I-II/IV.

The presence of reversible defects on MPS is associated with annual cardiac event rates ranging from approximately $3 \%$ to $10 \%$, in different diabetic populations. ${ }^{7,8,14,16}$ Furthermore, recent MPS studies have documented a positive relationship between the severity and extent of the perfusion defect and the cardiac event rate. ${ }^{6,13,16-19}$ However, the abovementioned annual event rates are lower than what one might expect based on the early observations from the LIPID trial and the study of Haffner et al, i.e. annual event rates were estimated to be $\pm 15-20 \% .^{20,21}$ Our findings that type 2 diabetic patients with anginal complaints (CCS I-II/IV) and severe reversible defects have a 3-6 fold higher annual event are in line with more recent studies. ${ }^{22,23}$

\section{Significance of a Normal MPS}

In the general population a normal MPS is associated with a low annual event rate of $\leq 1 \% .{ }^{17}$ The prognostic value of a normal MPS in type 2 diabetic patients has not yet been crystallized completely. Some of the aforementioned studies reported low cardiac event rates for patients with a normal MPS (1.2-2\%), although higher event rates of $2.5-3 \%$ were also described. ${ }^{7,8,13,16,24}$ These higher rates might be explained by the different populations studied: the use of insulin, inability to perform exercise-stress testing and the severity of complaints.

Awareness regarding the MPS definitions used is of importance when comparing event rates. Many investigators use a SSS $<4$ to define a normal MPS. In this study, we focused on reversible defects, using SDS $<3$ to define a non-ischemic MPS. This definition resulted in an annual event rate of $0.8 \%$. A SDS $<3$, however, does not rule out the presence of fixed defects and it therefore might lead to an overestimation of the event rate. The annual event rate of a clinical normal MPS (SDS $<3$ and SRS $<3$ ) was indeed lower $(0.4 \%)$.

Irrespective of the cut-off value used for normality, our favorable prognostic result of a normal MPS is comparable with event rates in the general population. This low event rate might be amplified by the fact that at time of screening, a high percentage of patients received risk modifying medication. Secondly, patients with an
LVEF $<35 \%$ were excluded from the study. An impaired LVEF is a well-known prognostic factor. ${ }^{25}$ The exclusion of patients with an LVEF $<35 \%$ might therefore have resulted in a lower event rate.

It has been suggested that the 'warrantee' period of a normal MPS in diabetics has a maximum of 2 years, after which the event rates will start to increase rapidly. ${ }^{8,18}$ The follow-up period of our population was too short to confirm or contradict this hypothesis.

\section{Insulin Use and Incidence of Cardiac Events}

In our study, the use of insulin was independently related to the occurrence of cardiac events. This finding is in line with several other studies, all concluding that patients requiring insulin are more likely to develop adverse events. ${ }^{20,26,27}$ This is most likely due to a more advanced state of diabetes and its related morbidity, including atherosclerosis. However, no relation was found with the duration of diabetes mellitus. This lack of relation might be explained by the fact that the majority of patients are diagnosed years after onset of the glucometabolic abnormalities, thereby negatively influencing the power of this variable. ${ }^{28}$

\section{Previous Myocardial Infarction and Incidence of Cardiac Events}

Previous myocardial infarction negatively influences outcome in both diabetic and non-diabetic patients. However, in our population this relation did not reach our beforehand defined level of significance $(P<.05)$. This is most likely due to sampling of the population.

\section{LIMITATIONS}

The premature discontinuation of the MERIDIAN trial resulted in a lower number of patients and a shorter follow-up period and consequently a low number of events. Furthermore, the current study was based on a pre-specified population with different treatment strategies; it is possible that the randomization has interfered with the outcome of the MPS-related cardiac event rate. However, no differences between the treatment strategies were observed in the MERIDIAN trial, and a recent study has found similar results in approximately 3,000 non-diabetic patients with stable coronary artery disease and evidence of myocardial ischemia. ${ }^{29}$

Theoretically there is a substantial chance of detecting spurious associations with the multivariable analysis described in this article; however, the outcome of this analysis confirms the results of previous studies in which these variables were also found to be independent predictors of cardiac death. 


\section{CONCLUSION AND CLINICAL IMPLICATIONS}

In our study, we found that type 2 diabetic patients with only mild anginal complaints present with a wide range of reversible perfusion defects on MPS. Patients with severe myocardial ischemia are at a 3-6 times higher risk of cardiac death and non-fatal MI compared to patients without or with moderate myocardial ischemia. The incidence of cardiac events in the patients with no or moderate ischemia, irrespective of the presence of fixed defects, is much lower than would have been expected based on previous studies. These findings are line with those of Hachamovitch et al. ${ }^{17}$ This implies that the amount ischemia determines appropriate therapeutic strategies. It is conceivable that these patients with no or moderate ischemia, conform their non-diabetic counterparts, will not benefit from an invasive approach and subsequent revascularization. Consequently it seems more reasonable to focus on life-style advices, optimized pharmacological therapy and close surveillance of symptoms. However, in patients with severe ischemia, a more aggressive and invasive approach seems justified.

\section{Acknowledgements}

We thank all investigators and coordinators of the MERIDIAN trial, all nuclear physicians, and medical and nursing staff in the recruitment and intervention centers who made the trial possible. The MERIDIAN trial was funded by The Dutch Heart Foundation and The Netherlands Organization for Health Research and Development. Financial support: The Dutch Heart Foundation and The Netherlands Organization for Health Research and Development.

\section{Open Access}

This article is distributed under the terms of the Creative Commons Attribution Noncommercial License which permits any noncommercial use, distribution, and reproduction in any medium, provided the original author(s) and source are credited.

\section{APPENDIX: ENROLLING CENTERS OF THE MERIDIAN TRIAL}

Amsterdam, Academic Medical Center, J.J. Piek;

Amsterdam, OLVG, G.J. Laarman;

Amsterdam VU Medical Center, G. Veen, J.G.F. Bronzwaer;

Amsterdam, Slotervaart Hospital, C.A. de Groot, C.E. Schotborgh;

Amsterdam, St. Lucas-Andreas Hospital, A.R. Willems;
Amsterdam, Boven-IJ Hospital, A.L.M. Bakx; Amstelveen, Amstelland Hospital, W.L. ten Holt; Almere, Flevo Hospital, A.S.J.M. Sadee; Apeldoorn, Gelre Hospitals, W.T.J. Jap Tjoen San; Blaricum, Gooi-Noord Hospital, G. Hoedemaker; Breda, Amphia Hospital, P.H.J.M. Dunselman; Eindhoven, Catharina Hospital, R.H. Michels; Groningen, Academic Medical Center, F. Zijlstra; Haarlem, Kennemer Hospital, E.G.B. de Vlies, G. Kan; Hengelo, Midden Twente Hospital, A. Derks; Hoorn, Westfries Gasthuis Hospital, C.L. Janus, D.C.G. Basart;

Maastricht, Academic Medical Center, C. de Zwaan, F.W.H.M Bär;

The Hague, Medical Center Haaglanden, L.H. Savalle; Zwolle, Isala Clinics, Weezenlanden and Sophia Hospital, H. Suryapranata, A.H.E.M. Maas.

\section{References}

1. King H, Aubert RE, Herman WH. Global burden of diabetes, 1995-2025: Prevalence, numerical estimates, and projections. Diabetes Care 1998;21:1414-31.

2. Kannel WB, McGee DL. Diabetes and glucose tolerance as risk factors for cardiovascular disease: The Framingham study. Diabetes Care 1979;2:120-6.

3. Stamler J, Vaccaro O, Neaton JD, Wentworth D. Diabetes, other risk factors, and 12-yr cardiovascular mortality for men screened in the Multiple Risk Factor Intervention Trial. Diabetes Care 1993;16:434-44.

4. Bonow RO, Gheorghiade M. The diabetes epidemic: A national and global crisis. Am J Med 2004;116:2-10.

5. Wackers FJ, Young LH, Inzucchi SE, Chyun DA, Davey JA, Barrett EJ, et al. Detection of silent myocardial ischemia in asymptomatic diabetic subjects: The DIAD study. Diabetes Care 2004;27:1954-61

6. Anand DV, Lim E, Lahiri A, Bax JJ. The role of non-invasive imaging in the risk stratification of asymptomatic diabetic subjects. Eur Heart J 2006;27:905-12.

7. Zellweger MJ, Hachamovitch R, Kang X, Hayes SW, Friedman JD, Germano G, et al. Prognostic relevance of symptoms versus objective evidence of coronary artery disease in diabetic patients. Eur Heart J 2004;25:543-50.

8. Giri S, Shaw LJ, Murthy DR, Travin MI, Miller DD, Hachamovitch R, et al. Impact of diabetes on the risk stratification using stress single-photon emission computed tomography myocardial perfusion imaging in patients with symptoms suggestive of coronary artery disease. Circulation 2002;105:32-40.

9. Wiersma JJ, Dijksman LE, Ten Holt WL, et al. Cardiac complications in type 2 diabetic patients with mild anginal complaints and documented reversible myocardial perfusion defects, results of the MERIDIAN trial. Neth Heart J 14, 409-16.

10. Depuey EG, Garcia EV. Updated imaging guidelines for nuclear cardiology procedures, part 1. J Nucl Cardiol 2001;8:G3-58.

11. Shaw LJ, Hendel R, Borges-Neto S, Lauer MS, Alazraki N, Burnette J, et al. Prognostic value of normal exercise and adenosine $(99 \mathrm{~m}) \mathrm{Tc}$-tetrofosmin SPECT imaging: Results from the multicenter registry of 4,728 patients. J Nucl Med 2003;44:134-9. 
12. Sharir T, Germano G, Kang X, Lewin HC, Miranda R, Cohen I, et al. Prediction of myocardial infarction versus cardiac death by gated myocardial perfusion SPECT: Risk stratification by the amount of stress-induced ischemia and the poststress ejection fraction. J Nucl Med 2001;42:831-7.

13. Berman DS, Kang X, Hayes SW, Friedman JD, Cohen I, Abidov A, et al. Adenosine myocardial perfusion single-photon emission computed tomography in women compared with men: Impact of diabetes mellitus on incremental prognostic value and effect on patient management. J Am Coll Cardiol 2003;41:1125-33.

14. Elhendy A, Huurman A, Schinkel AFL, Bax JJ, van Domburg RT, Valkema R, et al. Association of ischemia on stress $99 \mathrm{mTc}$-tetrofosmin myocardial perfusion imaging with all-cause mortality in patients with diabetes mellitus. J Nucl Med 2005;46: 1589-95.

15. Scholte AJHA, Bax JJ, Wackers FJT. Screening of asymptomatic patients with type 2 diabetes mellitus for silent coronary artery disease: Combined use of stress myocardial perfusion imaging and coronary calcium scoring. J Nucl Cardiol 2006;13:11-8.

16. Kang X, Berman DS, Lewin HC, Cohen I, Friedman JD, Germano $\mathrm{G}$, et al. Incremental prognostic value of myocardial perfusion single photon emission computed tomography in patients with diabetes mellitus. Am Heart J 1999;138:1025-32.

17. Hachamovitch R, Berman DS, Shaw LJ, Kiat H, Cohen I, Cabico $\mathrm{JA}$, et al. Incremental prognostic value of myocardial perfusion single photon emission computed tomography for the prediction of cardiac death: Differential stratification for risk of cardiac death and myocardial infarction. Circulation 1998;97:535-43.

18. Hachamovitch R, Hayes S, Friedman JD, Cohen I, Shaw LJ, Germano G, et al. Determinants of risk and its temporal variation in patients with normal stress myocardial perfusion scans: What is the warranty period of a normal scan? J Am Coll Cardiol 2003;41:1329-40.

19. Sharir T, Berman DS, Lewin HC, Friedman JD, Cohen I, Miranda $\mathrm{R}$, et al. Incremental prognostic value of rest-redistribution (201)Tl single-photon emission computed tomography. Circulation 1999;100:1964-70.

20. Haffner SM, Lehto S, Ronnemaa T, Pyorala K, Laakso M. Mortality from coronary heart disease in subjects with type 2 diabetes and in nondiabetic subjects with and without prior myocardial infarction. N Engl J Med 1998;339:229-34.
21. Keech A, Colquhoun D, Best J, Kirby A, Simes RJ, Hunt D, et al. Secondary prevention of cardiovascular events with long-term pravastatin in patients with diabetes or impaired fasting glucose: Results from the LIPID trial. Diabetes Care 2003;26:2713-21.

22. Becker A, Bos G, de Vegt F, Kostense PJ, Dekker JM, Nijpels G, et al. Cardiovascular events in type 2 diabetes: comparison with nondiabetic individuals without and with prior cardiovascular disease: 10-year follow-up of the Hoorn Study. Eur Heart J 2003;24:1406-13.

23. Heart Protection Study Collaborative G. MRC/BHF Heart Protection Study of cholesterol-lowering with simvastatin in 5963 people with diabetes: A randomised placebo-controlled trial. The Lancet 2003;361:2005-16.

24. Schinkel AFL, Elhendy A, Bax JJ, van Domburg RT, Huurman A, Valkema R, et al. Prognostic implications of a normal stress technetium-99m-tetrofosmin myocardial perfusion study in patients with a healed myocardial infarct and/or previous coronary revascularization. Am J Cardiol 2006;97:1-6.

25. Sharir T, Germano G, Kavanagh PB, Lai S, Cohen I, Lewin HC, et al. Incremental prognostic value of post-stress left ventricular ejection fraction and volume by gated myocardial perfusion single photon emission computed tomography. Circulation 1999; 100:1035-42.

26. Mathew V, Frye RL, Lennon R, Barsness GW, Holmes DR Jr. Comparison of survival after successful percutaneous coronary intervention of patients with diabetes mellitus receiving insulin versus those receiving only diet and/or oral hypoglycemic agents. Am J Cardiol 2004;93:399-403.

27. van der Schaaf RJ, Henriques JP, Wiersma JJ, Koch KT, Baan J Jr, Mulder KJ, et al. Primary percutaneous coronary intervention for patients with acute ST elevation myocardial infarction with and without diabetes mellitus. Heart 2006;92:117-8.

28. Taubert G, Winkelmann BR, Schleiffer T, Marz W, Winkler R, Gok R, et al. Prevalence, predictors, and consequences of unrecognized diabetes mellitus in 3266 patients scheduled for coronary angiography. Am Heart J 2003;145:285-91.

29. Boden WE, O'Rourke RA, Teo KK, Hartigan PM, Maron DJ, Kostuk WJ, et al. Optimal medical therapy with or without PCI for stable coronary disease. N Engl J Med 2007;356:1503-16. 